\title{
Fin whale survival and abundance in the Gulf of St. Lawrence, Canada
}

\author{
Christian Ramp ${ }^{1,2, *}$, Julien Delarue ${ }^{1}$, Martine Bérubé ${ }^{3}$, Philip S. Hammond ${ }^{2}$, \\ Richard Sears ${ }^{1}$
}

\author{
${ }^{1}$ Mingan Island Cetacean Study, 285 Green, St. Lambert, Quebec J4P 1T3, Canada \\ ${ }^{2}$ Sea Mammal Research Unit, Scottish Oceans Institute, University of St. Andrews, East Sands, St. Andrews, Fife KY16 8LB, UK \\ ${ }^{3}$ Marine Evolution and Conservation, Centre for Ecological and Evolutionary Studies, University of Groningen, \\ PO Box 11103, 9700 CC Groningen, The Netherlands
}

\begin{abstract}
The fin whale Balaenoptera physalus, the second largest species in the animal kingdom to have lived on Earth, was heavily targeted during the industrial whaling era. North Atlantic whaling for this species ended in 1987 and it is unclear if the populations are recovering. The stock structure in the North Atlantic is still under debate, but several lines of evidence suggest that fin whales in the Gulf of St. Lawrence may form a discrete stock with limited exchange with the rest of the North Atlantic. We applied mark-recapture models to 21 yr of photo-identification data from the Jacques-Cartier Passage to estimate the abundance and, for the first time, a survival rate based on live re-sightings for this stock of fin whales. Using the Cormack-Jolly-Seber model, we estimated a unisex non-calf apparent survival rate of 0.955 (95\% CI: 0.936 to 0.969 ) for the period 1990 to 2010, declining in the last $4 \mathrm{yr}$ of the study. The reduced survivorship was likely caused by a lower site fidelity combined with a higher mortality. The POPAN model yielded a super-population estimate of 328 individuals (95\% CI: 306 to 350) for the period 2004 to 2010, and confirmed the negative trend in apparent survival and annual abundance, indicating that the population has not increased since the last large-scale surveys from 1974 and 1997.
\end{abstract}

KEY WORDS: Fin whale $\cdot$ Mark-recapture $\cdot$ Survival $\cdot$ Abundance $\cdot$ Modeling Resale or republication not permitted without written consent of the publisher

\section{INTRODUCTION}

The fin whale Balaenoptera physalus is the second largest species that has lived on Earth. The commercial hunt in the North Atlantic ended in 1987 and the species globally is regarded as Endangered by the International Union for Conservation of Nature (IUCN) (Reilly et al. 2008). Fin whales are mostly found in temperate and high-latitude feeding grounds during summer, and some populations undergo a migration to warmer waters in winter (Rice 1998). However, there is no clear migration between feeding and breeding grounds as in humpback whales Megaptera novaeangliae or right whales Eubalaena spp., and fin whale songs - a male breeding display — have been recorded in high latitudes year round (Clark 1995). Despite decades of exploitation and research, our knowledge of fin whales' life history and population structure is limited.

The International Whaling Commission (IWC) has defined a number of stock structure hypotheses for fin whales in the North Atlantic with 2, 3 and 4 stocks/ populations. Seven feeding grounds have been identified but it remains unknown where any of the populations breed (IWC 2009). Genetic analysis showed significant differences between the Mediterranean Sea, the Northeast Atlantic, and the Northwest Atlantic, with some mixing of the latter 2 occurring around Iceland and Greenland (Bérubé et al. 1998, Palsbøll et al. 2004). Mitchell (1974) suggested at 
least 2 distinct stocks in the western North Atlantic, one in the waters centered around Nova Scotia and one off Newfoundland and Labrador, which was supported by the re-analysis of catch data from Canadian shore whaling stations (Breiwick 1993). Sergeant (1977) hypothesized that the animals in the Gulf of St. Lawrence (GSL) could form a separate stock, presumably wintering in the Laurentian Channel near the entrance of the Gulf, their movements dictated by expanding and retreating sea ice. Analyses of contaminant levels (Hobbs et al. 2001) and of song structure (Delarue et al. 2009) give support to this hypothesis. Photo-identification studies showed that limited exchange exists with the Nova Scotia stock, which includes Gulf of Maine individuals (Coakes et al. 2005, Robbins et al. 2007). We adopt the definition of a stock from the US Marine Mammal Protection Act (Wade \& Angliss 1997), in which a stock is defined as a demographically isolated biological population where internal demographics (births and deaths) are far more important for the population than external dynamics (immigration and emigration). For the present study, we regard the GSL as a separate stock with occasional exchange with stocks in adjacent waters.

Mitchell (1974) analyzed data from ship-based surveys and estimated that there were 340 fin whales in the GSL and 2800 in Nova Scotian waters. Summer aerial surveys in 1995 and 1996 yielded an estimate of 340 to 380 animals in the GSL (Kingsley \& Reeves 1998). The last aerial surveys in 2007 resulted in a combined estimate of 462 (95\% CI: 270 to 791) animals for the GSL and the Scotian Shelf (Lawson \& Gosselin 2009), although most sightings occurred on the Scotian Shelf. Both aerial surveys are likely underestimates, especially the recent one, because it was not corrected for animals missed on the track line. For the Northwest Atlantic, the most recent abundance estimate is 3522 (coefficient of variation: 0.27) (Waring et al. 2013). Fin whale natural adult annual mortality rate has been estimated to range between 0.04 and 0.06 (Clark 1982, de la Mare 1985). Some parts of the GSL see a lot of marine traffic, and the fin whale is the species most frequently involved in collisions with large vessels (Laist et al. 2001), although it is unclear why.
The Quebec stranding network recorded 20 dead fin whales from 2004 to 2010 (Quebec Marine Mammal Emergency Network Call Center Reports 20042010), raising questions as to whether this level of mortality is sustainable. In the present paper, we analyze 21 years of fin whale photo-identification data to estimate for the first time a survival rate based on live sighting-re-sighting data and not on whaling data. In addition, we produce an updated abundance estimate for the GSL stock.

\section{MATERIALS AND METHODS}

\section{Data collection}

We conducted multiple annual surveys in the Jacques-Cartier Passage (JCP) and adjacent waters in the GSL, Canada (Fig. 1) from 1982. Weather permitting, one or several inflatable boats surveyed the region for baleen whales. The average season lasted from the end of May/beginning of June to mid/end of October, with an average annual effort of 60 survey days and $\sim 500 \mathrm{~h}$ of observation. Surveys were designed to maximize the photo-identification effort. We used standard single lens reflex (SLR) $35 \mathrm{~mm}$ cameras with black and white film until 2003 and switched to digital SLR cameras from 2004 on to

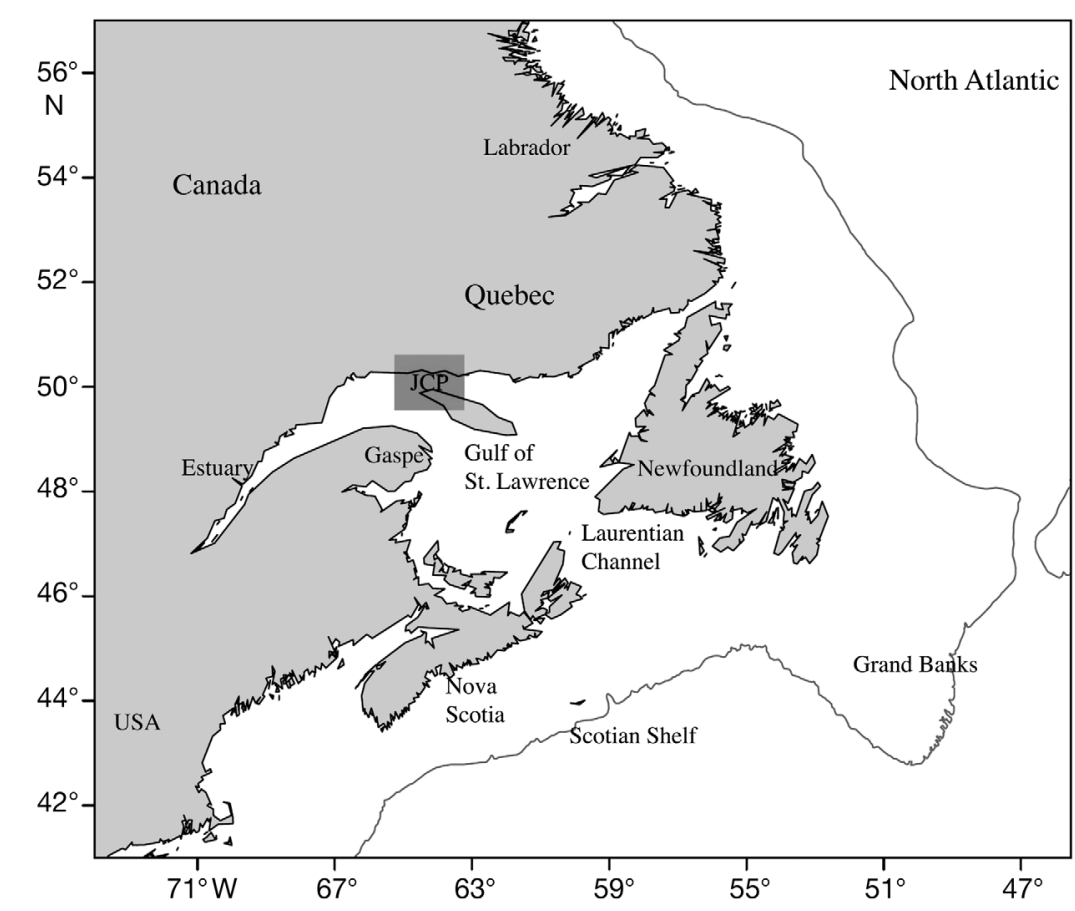

Fig. 1. Eastern Canadian waters, with the research area Jacques-Cartier Passage (JCP) marked dark gray 
identify individual fin whales using their unique pigmentation pattern on their right side and the shape of their dorsal fin (Agler et al. 1990). The sex of an individual was determined by molecular analysis (Bérubé \& Palsbøll 1996) of genomic DNA extracted from remotely collected skin biopsy samples (Palsbøll et al. 1992) since 1990.

We used the capture history of the identified fin whales from 1990 to 2010 to model the survival probability of fin whales, using years as sampling occasions. For this, we regarded an animal as captured for a given year when high-quality photos were taken, regardless of how often an animal was sighted in a given year. Animals sighted more regularly have a greater chance of being biopsied and hence sexed. This results in an overestimation of survival rates for sexed and an underestimation for unsexed animals (Nichols et al. 2004). The same authors presented several solutions to overcome this bias, and we applied their ad hoc approach, which results in unbiased survival estimates (Nichols et al. 2004). We used only sexed individuals, conditioned to when the animal was biopsied, and did not apply the information on sex in retrospect. Thus, an animal entered the population only in the year it was sexed, and previous sightings were omitted. For abundance estimates, we used all animals from the years 2004 to 2010 due to enhanced identification possibilities using digital photography and image processing software, resulting in a higher recapture rate. We omitted calves from the analysis because their sighting is dependent on that of their mother, and their survival is assumed to be lower than that of adults, as shown for gray whales Eschrichtius robustus and humpback whales Megaptera novaeangliae (Reilly 1984, Barlow \& Clapham 1997, Gabriele et al. 2001). We therefore estimate non-calf survival and a population estimate for animals older than $1 \mathrm{yr}$.

\section{Data analysis}

\section{Modeling survival}

The Cormack-Jolly-Seber model (CJS) (Cormack 1964, Jolly 1965, Seber 1965) estimates the survival probability $(\phi)$ in the population at risk of capture in the interval between 2 successive sampling occasions for individuals caught and alive in the first sampling event, and the probability of recapture $(p)$ of those individuals on each sampling occasion (Burnham \& Anderson 1992). The estimated apparent survival probability is the product of the true survival probability and the probability of return of animals to the study area (site fidelity). Henceforth, for simplicity, we refer to this as survival rate. We allowed the probability of survival and recapture to vary due to a number of effects, including time (sampling occasion, $t)$, linear temporal trend $(T)$, sex $(s)$, and trap dependency $(m)$ following the notation of Burnham et al. (1987), Lebreton et al. (1992), and Sandland \& Kirkwood (1981); a parameter constant over time was noted as (.). Additive (+) and interaction $\left({ }^{*}\right)$ effects, e.g. $s+t, s^{*} t$ (representing $s+t+s \times t$ ), were also explored. Sex $(s)$ referred to 2 groups, females and males. We did not regard trap dependency as genuinely representing dependence on capture, but rather as accounting for structural effects mimicking trap dependency, following (Pradel 1993). We added this effect as an individual covariate, taking into account whether or not the animal was sighted on the previous sampling occasion. We applied the CJS model to the dataset 1990 to 2010, the period during which information on sex of the animals was available.

\section{Modeling abundance}

The POPAN model (Schwarz \& Arnason 1996) is a parameterization of the Jolly-Seber (JS) (Jolly 1965, Seber 1965) model that estimates, in addition to apparent survival $(\phi)$ and probability of (re)capture $(p)$, the probability of entry into the population $(b)$ and the abundance of the super-population $(\mathrm{N})$. Under the JS model, the probability of survival and the probability of (re)capture include both marked and unmarked animals, in contrast to the CJS model, which takes only marked animals into account. The JS model relies on the assumption that each animal, marked and unmarked, has the same probability of (re)capture, because the model uses the ratio of marked to unmarked animals to estimate abundance. We used the dataset from 2004 to 2010 to estimate abundance, because of the larger sample size in these years resulting from the advances of digital photography and image processing software. The estimate of the abundance $(\mathrm{N})$ of the super-population encompasses the entire study period, thus all animals alive between 2004 and 2010 .

\section{Goodness-of-fit testing and model selection}

We applied goodness-of-fit (GOF) tests in an open population model framework using the program U- 
CARE (Choquet et al. 2005) to test if a general model fitted the data adequately well with respect to the assumptions. U-CARE includes 4 tests of different aspects of the model fit (for details, see Burnham et al. 1987, Choquet et al. 2005), and provides an estimation of the extra-binominal variation, the so-called over-dispersion (variance inflation) factor $\hat{c}$. Additionally, U-CARE provides 2 direct tests, one for trapdependence and one for transience.

Model selection was based on the Akaike information criterion (Akaike 1985, Burnham \& Anderson 2002), corrected for small sample size $\left(\mathrm{AIC}_{\mathrm{C}}\right)$ using the program MARK (White \& Burnham 1999). The model with the lowest $\mathrm{AIC}_{\mathrm{C}}$ value has the best fit using the fewest parameters. When the difference in the $\mathrm{AIC}_{\mathrm{C}}\left(\Delta \mathrm{AIC}_{\mathrm{C}}\right)$ between 2 models is $<2$, both models are inferred to have similar support from the data. If $\Delta \mathrm{AIC}_{\mathrm{c}}>2$ but $<7$, low support is inferred for the least likely model, and models with a $\Delta \mathrm{AIC}_{\mathrm{C}}>10$ are regarded as having no support. When several models showed some support, we applied a model-averaging procedure in which the parameters were estimated from the models in question proportional to their $\mathrm{AIC}_{\mathrm{C}}$ weights. When we applied the variance inflation factor $\hat{\mathrm{c}}$, the model selection was based on the quasi-AIC ${ }_{\mathrm{C}}\left(\mathrm{QAIC}_{\mathrm{C}}\right.$ ) (Burnham \& Anderson 2002).

\section{RESULTS}

\section{Modeling survival}

We identified 422 fin whales from 1982 to 2010, including 96 males, 59 females, and 267 unsexed animals. We restricted the analysis to only sexed animals conditioned to the time when they were first sexed. This resulted in 155 animals from 1990 onwards. The time-dependent CJS model $\left[\phi\left(s^{*} t\right) p\right.$ $\left.\left(s^{*} t\right)\right]$ was accepted by the GOF test $\left(\chi^{2}=104.33\right.$, df $=113, \mathrm{p}=0.707)$. The test details showed that 1 test component (TEST2.CT; see Burnham et al. 1987, Choquet et al. 2005 for details) was marginal for both males and females, and the direct test for trapdependence was significant for both sexes. The $\hat{c}$ was $<1$ and we based model selection on $\mathrm{AIC}_{\mathrm{C}}$. The model selection process did not support differentiation between males and females for either $\phi$ or $p$, so the sexes were pooled (Table 1). We added immediate trap response in the model $\left[\phi(t) p\left(t^{*} m\right)\right]$ following Pradel (1993). The fully time-dependent model had many inestimable parameters. Time dependency was not supported for the estimation of $\phi$, but the results showed lower survival estimates for the last
Table 1. Cormack-Jolly-Seber (CJS) models selected, ordered by their value for the Akaike information criterion corrected for small sample size $\left(\mathrm{AIC}_{\mathrm{c}}\right)$. The notation $\phi(. /$.$) de-$ notes the 2 constant survival estimates for the periods 1990-2007 and 2008-2010. $\Delta \mathrm{AIC}_{\mathrm{c}}$ : difference in $\mathrm{AIC}_{\mathrm{c}} \mathrm{Com}-$ pared to best supported model; wt: weight; param.: parameters; deviance: deviance explained by the model $; \phi$ : survival probability; $p$ : probability of recapture; $t$ : time (sampling occasion); $T$ : linear temporal trend; $s$ : sex; $m$ : trap dependency

\begin{tabular}{|lccccc|}
\hline Model & $\mathrm{AIC}_{\mathrm{c}}$ & $\Delta \mathrm{AIC}_{\mathrm{c}}$ & $\begin{array}{c}\mathrm{AIC}_{\mathrm{c}} \\
\mathrm{wt}\end{array}$ & $\begin{array}{c}\text { No. } \\
\text { param. }\end{array}$ \\
& & \multicolumn{4}{c}{ Deviance } \\
\hline$\phi() p.(t+m)$ & 1339.47 & 0.00 & 0.70 & 22 & 1293.34 \\
$\phi(. /) p(t+m)$ & 1341.52 & 2.06 & 0.25 & 23 & 1293.20 \\
$\phi() p.\left(t^{*} m\right)$ & 1344.82 & 5.35 & 0.05 & 41 & 1255.28 \\
$\phi(. /) p(t)$ & 1359.09 & 19.63 & 0 & 22 & 1312.97 \\
$\phi() p.(t)$ & 1360.97 & 21.51 & 0 & 21 & 1317.04 \\
$\phi(T) p(t)$ & 1362.28 & 22.82 & 0 & 22 & 1316.16 \\
$\phi(s) p(t)$ & 1363.16 & 23.69 & 0 & 22 & 1317.03 \\
$\phi(t) p(t+m)$ & 1367.37 & 27.90 & 0 & 40 & 1280.21 \\
$\phi() p.\left(s^{*} t\right)$ & 1384.35 & 44.88 & 0 & 41 & 1294.81 \\
$\phi(t) p(t)$ & 1384.89 & 45.43 & 0 & 39 & 1300.10 \\
$\phi(s) p\left(s^{*} t\right)$ & 1386.45 & 46.98 & 0 & 42 & 1294.52 \\
$\phi(t) p\left(t^{*} m\right)$ & 1371.70 & 32.22 & 0 & 58 & 1240.14 \\
$\phi(t) p\left(s^{*} t\right)$ & 1412.22 & 72.75 & 0 & 59 & 1278.09 \\
$\phi\left(s^{*} t\right) p(t)$ & 1426.17 & 86.70 & 0 & 59 & 1292.04 \\
$\phi\left(s^{*} t\right) p\left(s^{*} t\right)$ & 1458.00 & 118.53 & 0 & 79 & 1269.83 \\
\hline
\end{tabular}

4 yr. Inclusion of a trend $(T)$ in the probability of survival did not improve the model fit. We therefore built a model with constant but different survival rates for the periods 1990-2006 and 2007-2010. This model did not improve the model with constant survival, but had similar support $\left(\triangle \mathrm{AIC}_{\mathrm{c}}\right.$ of 2$)$.

The best-supported model ( $\mathrm{AIC}_{\mathrm{C}}$ weight: 0.70) resulted in a survival rate of 0.955 (95\% CI: 0.936 to 0.969). The second best model estimated an identical survival rate for the period 1990 to 2006 (0.956) and a reduced survival of 0.940 (95\% CI: 0.792 to 0.985$)$ for the period 2007 to 2010. Due to the model uncertainty, we model-averaged the results over all models with support (Table 1), and the results for $\phi$ were 0.955 (95\% CI: 0.936 to 0.969 ) for $1990-2006$ and 0.951 (95\% CI: 0.883 to 0.981 ) for $2007-2010$. The estimates for recapture probability are given in Fig. 2.

\section{Modeling abundance \\ POPAN model}

In the period 2004 to 2010, we identified 290 fin whales. We pooled all animals in one single group. We applied the GOF test for the CJS model $[\phi(t) p(t)]$ as an approximation and it was rejected $\left(\chi^{2}=32.3\right.$, df 


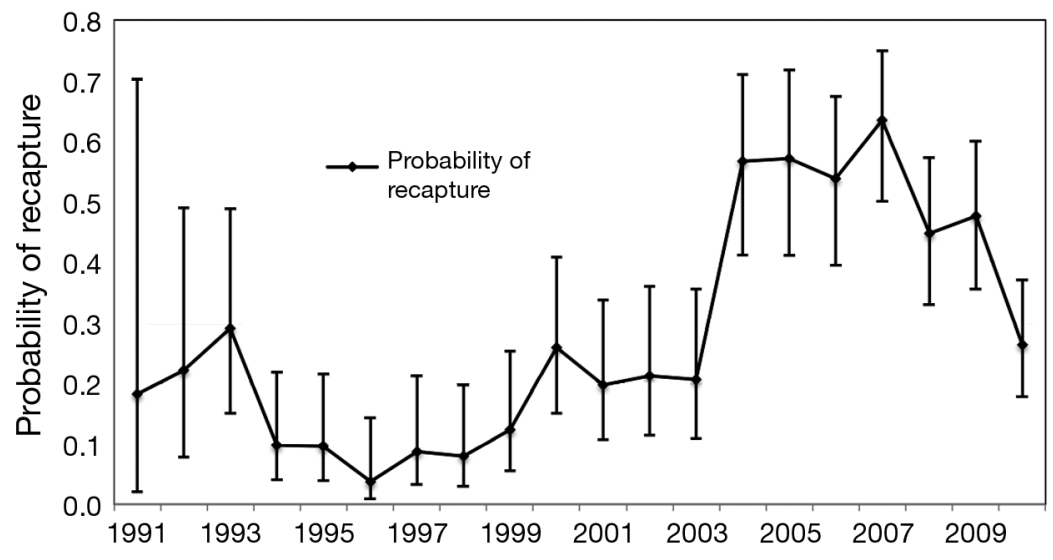

Fig. 2. Model-averaged estimates of the probability of recapture ( $p$ ) for fin whales Balaenoptera physalus over the study period 1990 to 2010 from the best-fitting Cormack-Jolly-Seber (CJS) models

\section{DISCUSSION}

The long-term estimate of the survival rate of non-calf fin whales in the GSL was 0.955 (95\% CI: 0.936 to 0.969 ), but survival declined towards the end of the study. This phenomenon was shown by the CJS model using only sexed animals and by the POPAN parameterization applied to all animals.

The apparent survival rate is the product of the true survival rate and site fidelity; thus the decrease in the apparent survival rate could be caused by a decrease in either of the 2 or in both. In general, the decrease in the last years shown by the POPAN model (Fig. 3) seems too steep to be explained by an increase in $=18, \mathrm{p}=0.02)$. Only one test component (TEST3.SR; see Burnham et al. 1987, Choquet et al. 2005 for details) was significant $\left(\chi^{2}=13.6, \mathrm{df}=5, \mathrm{p}=0.018\right)$, as well as the direct test for transience. POPAN does not allow adjusting for transience, and we applied the estimated $\hat{c}$ of 1.79. Model selection was therefore based on QAIC $_{\mathrm{c}}$.

The best supported model had a (negative) trend for the probability of survival, constant probability of capture, and time-dependent probability of entry [model $\phi(T) p() b.(t) \mathrm{N}($.$) ], with an \mathrm{AIC}_{\mathrm{c}}$ weight of 0.73 (Table 2). The model-averaged estimate for the population size was 328 (95\% CI: 306 to 350 ). The model-averaged estimates of $\phi$ and $p$ are shown in Fig. 3. The model-averaged estimates for $b$ fluctuated highly, with two unable to be estimated, and are not shown. In Table 3, we show the derived annual population estimates for the years 2005 to 2010 . These estimates are much lower than the super-population estimate, and they show a decline in recent years.

Table 2. POPAN models selected, ordered by their value for the quasi-Akaike information criterion corrected for small sample size $\left(\mathrm{QAIC}_{\mathrm{c}}\right)$. b: probability of entry into the population; N: abundance of the super-population. See Table 1 for other abbreviations and description of models

\begin{tabular}{|lcccc|}
\hline Model & QAIC $_{\mathrm{c}}$ & $\Delta$ QAIC $_{\mathrm{c}}$ & $\begin{array}{c}\mathrm{QAIC}_{\mathrm{c}} \\
\text { wt }\end{array}$ & $\begin{array}{c}\text { No. } \\
\text { param }\end{array}$ \\
\hline$\phi(T) p() b.(t) \mathrm{N}()$. & 915.14 & 0.00 & 0.73 & 10 \\
$\phi(T) p(t) b(t) \mathrm{N}()$. & 919.15 & 4.01 & 0.10 & 15 \\
$\phi(t) p() b.(t) \mathrm{N}()$. & 919.49 & 4.35 & 0.08 & 14 \\
$\phi() p.(t) b(t) \mathrm{N}()$. & 919.65 & 4.52 & 0.08 & 14 \\
$\phi(t) p(t) b(t) \mathrm{N}()$. & 925.12 & 9.98 & 0.01 & 20 \\
$\phi() p.() b.(t) \mathrm{N}()$. & 928.00 & 12.86 & 0.00 & 10 \\
$\phi() p.() b.(.) \mathrm{N}()$. & 958.39 & 43.25 & 0.00 & 4 \\
\hline
\end{tabular}
mortality alone. In 2010, only 72 animals were identified, compared to 169 in 2006. In more recent years, fewer animals frequented the $\mathrm{JCP}$, which is not the only area where fin whales are sighted in the GSL (Kingsley \& Reeves 1998), but is home to the largest

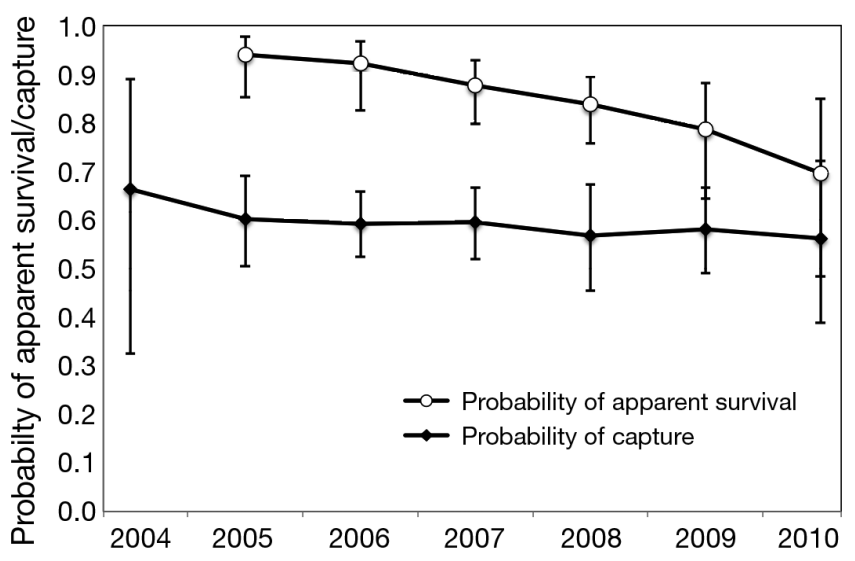

Fig. 3. Model-averaged estimates for the probability of survival $(\phi)$ and capture $(p)$ from 2004 to 2010 for fin whales Balaenoptera physalus from the best-fitting POPAN models

Table 3. Model-averaged annual derived population estimates for fin whales Balaenoptera physalus for 2005 to 2010 from the best-fitting POPAN parameterization

\begin{tabular}{|lcc|}
\hline Year & Population estimate & $95 \%$ CI \\
\hline 2005 & 166 & $134-197$ \\
2006 & 264 & $237-291$ \\
2007 & 232 & $203-261$ \\
2008 & 200 & $170-231$ \\
2009 & 163 & $127-199$ \\
2010 & 133 & $76-191$ \\
\hline
\end{tabular}


known aggregation in the Gulf. However, the annual number of animals frequenting these waters varies greatly, likely due to prey distribution in the Gulf. Therefore, it seems that a decrease in site fidelity was at least partly responsible for the decline in apparent survival.

The POPAN model results confirm the decline in survival. Over the 2004-2010 period, 20 dead fin whales were recorded within the GSL (Quebec Marine Mammal Emergency Network Call Center Reports 2004-2010). Given the low human population density along the shores of the GSL and the fact that carcasses of rorqual whales are known to sink rapidly (Michael Moore pers. comm.), the number of unreported cases might be substantially higher. Three animals were found entangled in fishing gear, while 4 animals showed signs of vessel collisions. Due to the lack of funding for necropsies, the cause of death remains unknown, but an annual average of almost 3 recorded dead whales $(\sim 1 \%$ of the estimated population size) seems high. We do not know if these numbers have increased, because the stranding network records only started in 2004.

Marine traffic in the study area has been increasing over the study period (C. Ramp pers. obs.), and fin whales are frequently involved in vessel collisions (Laist et al. 2001). Furthermore, fin whales have shifted their temporal occurrence in the Gulf and arrived about a month earlier in 2010 than at the beginning of the study (Mingan Island Cetacean Study, MICS unpubl. data). This shift increased their overlap with the snow crab fisheries along the Quebec North Shore, which ends around mid-July, and raised the risk of entanglements. Therefore, we suggest that the high number of reported deaths in addition to an unknown number of mortalities was partly responsible for the pronounced decrease in survival for sexed individuals.

We consider the unisex survival rate of 0.955 (95\% CI: 0.936 to 0.969 ) to be the best available estimate for GSL fin whales for 2 reasons. First, the survival rate remained constant for most of the study period. Second, the estimate is also in the range of survival rates of other long-living baleen whales such as humpbacks (0.96 for non-calves; Barlow \& Clapham 1997, Larsen \& Hammond 2004) and blue whales Balaenoptera musculus (0.975; Ramp et al. 2006). However, the survival rate of the here analyzed fin whale population in recent years was lower.

The super-population estimate of 328 (95\% CI: 306 to 350 ) animals from the POPAN model is very close to the estimate from Mitchell (1974) of 340 for the late 1960s and from Kingsley \& Reeves (1998) of 380 ani- mals in the early 1990 s, although the latter authors offer the advice to regard their estimate cautiously. Taken at face value, these numbers indicate that the population has not increased over the last $50 \mathrm{yr}$. The 2 earlier studies used line transect methods for their estimates and covered large areas of the GSL, while our study was based on mark-recapture data collected in only a small portion of the Gulf. In addition, our estimate of 328 represents the number of animals alive at any time during the study period (2004 to 2010), while the former estimates (Mitchell 1974, Kingsley \& Reeves 1998) are for one specific point in time. Our annual estimates (Table 3) are much lower. Our estimate was likely biased towards the high side due to the occurrence of transience in the data. By definition, transient animals are captured once and leave the study area permanently, and hence are not available for recapture (Pradel et al. 1997). This biases the survival rate towards the low side, and biases the population estimate towards the high side.

Despite these biases, we think that the POPAN parameterization is an adequate tool for the biological situation in which the study species is characterized by high survival and low reproduction and when it is only applied to a relatively short study period. The results indicate that some fin whales are not returning to the JCP every year but are part of the overall population. Although the significance of the JCP to the overall GSL population is unclear, the large number of whales encountered in some years (just around half of the estimated population in 2006) suggests that we encountered a large proportion of the population over the 2004 to 2010 study period. Indeed, the total number of identified animals ( $\mathrm{n}=$ 290) was close to the estimate of the super-population $(\mathrm{N}=328)$. This, combined with sighting data showing movements between Gaspé, the Estuary (2 other feeding areas; Fig. 1), and the JCP (MICS unpubl. data), suggests that the JCP is an important area for GSL fin whales and that our estimate is a realistic estimate of the whole population.

Although the reported decrease in apparent survival is likely partly caused by a reduction in site fidelity, true mortality may have increased recently. We do not know the number of dead animals, but an average of 3 dead animals $(\sim 1 \%$ of the estimated population) reported per year is noteworthy, and the real number of deaths must certainly be higher. Such mortality might not be sustainable, especially if the demographic isolation of the presumed GSL stock is confirmed. Furthermore, maritime traffic will increase in the future due to the expanding mining activities in northern Quebec and the potential open- 
ing of the Northwest Passage (Barnes 2008). This will increase the risk of ship strikes for this relatively small and possibly isolated stock. More work is needed to evaluate the significance of the JCP to the whole GSL fin whale stock, the demographic isolation of that stock, and the reasons behind the decrease in survival.

Acknowledgements. Mingan Island Cetacean Study (MICS) thanks the numerous volunteers and team members, especially Alain Carpentier, for data collection and handling over all these years. We also thank Thomas Doniol-Valcroze for feedback and advice on all parts of this work, and Jim Nichols and Carl Schwarz for statistical advice on the various models. All fieldwork was conducted under permits from the Department of Fisheries and Oceans Canada.

\section{LITERATURE CITED}

Agler BA, Beard JA, Bowman RS, Corbett HD and others (1990) Fin whale (Balaenoptera physalus) photographic identification: methodology and preliminary results from the western North Atlantic. In: Hammond PS, Mizroch SA, Donovan GP (eds) Rep Int Whal Comm Spec Issue 12:349-356

Akaike H (1985) Prediction and entropy. In: Atkinson AC, Fienberg SE (eds) A celebration of statistics: the ISI centenary volume. Springer Verlag, New York, NY, p 1-24

Barlow J, Clapham PJ (1997) A new birth-interval approach to estimating demographic parameters of humpback whales. Ecology 78:535-546

Barnes A (2008) Cost minimizing route choice for marine transportation: expected vessel traffic through the Nortwest Passage 2050-2100. Sample paper for Kendrick DA, Mercado PR, Amman HM: Computational economics. Available at www.laits.utexas.edu/compeco/ Sample_Papers/Barnes/Cost-Minimizing_Route_Choice_ for_Marine_Transportation_BARNES.pdf

Bérubé M, Palsbøll PJ (1996) Identification of sex in cetaceans by multiplexing with three ZFX and ZFY specific primers. Mol Ecol 5:283-287

Bérubé M, Aguilar A, Dendanto D, Larsen F and others (1998) Population genetic structure of North Atlantic Mediterranean Sea and Sea of Cortez fin whales, Balaenoptera physalus (Linnaeus 1758): analysis of mitochondrial and nuclear loci. Mol Ecol 7:585-599

Breiwick JM (1993) Population dynamics and analyses of the fisheries for fin whales (Balaenoptera physalus) in the Northwest Atlantic Ocean. PhD thesis, University of Washington, Seattle

Burnham KP, Anderson DR (1992) Data based selection of an appropriate biological model: the key to modern data analysis. In: McCullough DR, Barerett RH (eds) Wildlife 2001: populations. Springer Verlag, New York, NY, p 16-30

Burnham KP, Anderson DR (2002) Model selection and multimodel inference: a practical information-theoretic approach, 2nd edn. Springer, Berlin

Burnham KP, Anderson DR, White GC, Brownie C, Pollock $\mathrm{KH}$ (1987) Design and analysis methods for fish survival experiments based on release recapture. Am Fish Soc Monogr 5

Choquet R, Reboulet AM, Lebreton JD, Gimenez O, Pradel R (2005) U-CARE 2.2 user's manual. CEFE, UMR 5175, CNRS, Montpellier

Clark WG (1982) Historical rates of recruitment to Southern Hemisphere fin whale stocks. Rep Int Whal Comm 32: 305-324

Clark CW (1995) Application of US Navy underwater hydrophone arrays for scientific research on whales. Rep Int Whal Comm 45:210-222

Coakes A, Gowans S, Simard P, Giard J, Vashro C, Sears R (2005) Photographic identification of fin whales (Balaenoptera physalus) off the Atlantic coast of Nova Scotia, Canada. Mar Mamm Sci 21:323-326

Cormack R (1964) Estimates of survival from the sighting of marked animals. Biometrika 51:429-438

de la Mare WK (1985) On the estimation of mortality rates from whale age data, with particular reference to minke whales (Balaenoptera acutorostrata) in the Southern Hemisphere. Rep Int Whal Comm 35:239-250

Delarue J, Todd SK, Van Parijs SM, Di Iorio L (2009) Geographic variation in Northwest Atlantic fin whale (Balaenoptera physalus) song: implications for stock structure assessment. J Acoust Soc Am 125:1774-1782

Gabriele CM, Straley JM, Mizroch SA, Baker CS and others (2001) Estimating the mortality rate of humpback whale calves in the central North Pacific Ocean. Can J Zool 79: $589-600$

> Hobbs KE, Muir DC, Mitchell E (2001) Temporal and biogeographic comparisons of PCBs and persistent organochlorine pollutants in the blubber of fin whales from eastern Canada in 1971-1991. Environ Pollut 114: 243-254

IWC (International Whaling Commission) (2009) Report of the Scientific Committee, Report of the Sub-committee on the Revised Management Procedure, Annex D, Appendix 6. J Cetacean Res Manag 11:114-131

Jolly GM (1965) Explicit estimates from capture-recapture data with both death and immigration-stochastic model. Biometrika 52:225-247

Kingsley MCS, Reeves RR (1998) Aerial surveys of cetaceans in the Gulf of St. Lawrence in 1995 and 1996. Can J Zool 76:1529-1550

Laist DW, Knowlton AR, Mead JG, Collet AS, Podesta M (2001) Collisions between ships and whales. Mar Mamm Sci 17:35-75

Larsen F, Hammond PS (2004) Distribution and abundance of West Greenland humpback whales (Megaptera novaeangliae). J Zool (Lond) 263:343-358

Lawson JW, Gosselin JF (2009) Distribution and preliminary abundance estimates for cetaceans seen during Canada's marine megafauna survey - a component of the 2007 TNASS. DFO Can Sci Advis Sec Res Doc 2009/031

Lebreton JD, Burnham KP, Clobert J, Anderson DR (1992) Modeling survival and testing biological hypotheses using marked animals - a unified approach with case studies. Ecol Monogr 62:67-118

Mitchell ED (1974) Present status of northwest Atlantic fin and other whale stocks. In: The whale problem: a status report. Harvard University Press, Cambridge, MA, p 108-169

Nichols JD, Kendall WL, Hines JE, Spendelow JA (2004) Estimation of sex-specific survival from capture-recap- 
ture data when sex is not always known. Ecology 85: 3192-3201

Palsbøll PJ, Vader A, Bakke I, Elgewely MR (1992) Determination of gender in cetaceans by the polymerase chain reaction. Can J Zool 70:2166-2170

Palsbøll PJ, Bérubé M, Aguilar A, Notarbartolo-Di-Sciara G, Nielsen R (2004) Discerning between recurrent gene flow and recent divergence under a finite-site mutation model applied to North Atlantic and Mediterranean Sea fin whale (Balaenoptera physalus) populations. Evolution 58:670-675

Pradel R (1993) Flexibility in survival analysis from recapture data: handling trap dependence. In: Lebreton JD, North PM (eds) Marked individuals in the study of bird populations. Birkhäuser Verlag, Basel, p 29-37

Pradel R, Hines JE, Lebreton JD, Nichols JD (1997) Capturerecapture survival models taking account of transients. Biometrics 53:60-72

Quebec Marine Mammal Emergency Network/Réseau québécois d'urgences pour les mammifères marins (20042010). Annual reports 2004-2010. Groupe de recherche et d'éducation sur les mammifères marins (GREMM), Tadoussac, Québec

> Ramp C, Bérubé M, Hagen W, Sears R (2006) Survival of adult blue whales Balaenoptera musculus in the Gulf of St. Lawrence, Canada. Mar Ecol Prog Ser 319: $287-285$

Reilly SB (1984) Observed and published rates of increase in gray whales, Eschrichtius robustus. Rep Int Whal Comm Spec Issue 6:389-399

Reilly SB, Bannister JL, Best PB, Brown M and others (2008)

Editorial responsibility: Nils Bunnefeld, Stirling, UK
Balaenoptera physalus. In: IUCN 2012. IUCN Red List of Threatened Species, version 2012.2

Rice DW (1998) Marine mammals of the world: systematics and distribution. No. 4. Society for Marine Mammalogy, Lawrence, KS

Robbins J, Dendanto D, Giard J, Panigada S, Sears R, Zanardelli M (2007) Photo-ID studies of fin whales in the North Atlantic Ocean and the Mediterranean Sea. Rep Sci Comm Int Whal Comm SC/59/PF11:1-4

Sandland R, Kirkwood G (1981) Estimation of survival in marked populations with possibly dependent sighting probabilities. Biometrika 68:531-541

Schwarz CJ, Arnason AN (1996) A general methodology for the analysis of capture-recapture experiments in open populations. Biometrics 52:860-873

Seber GAF (1965) A note on the multiple-recapture census. Biometrika 52:249-259

Sergeant DE (1977) Stocks of fin whales Balaenoptera physalus L. in the North Atlantic Ocean. Rep Int Whal Comm 27:460-473

Wade PR, Angliss R (1997) Guidelines for assessing marine mammal stocks: report of the GAMMS Workshop, April 3-5, 1996, Seattle, Washington. NOAA Tech Memo NMFS-OPR-12. US Department of Commerce,

Waring GT, Josephson E, Maze-Foley K, Rosel PE (2013) U.S. Atlantic and Gulf of Mexico marine mammal stock assessment-2012. NOAA Tech Memo NMFS-NE-223. National Marine Fisheries Service, Woods Hole, MA. http://nefsc.noaa.gov/publications/tm/tm223/

White GC, Burnham KP (1999) Program MARK: survival estimation from populations of marked animals. Bird Study 46(Suppl 001):S120-S139

Submitted: June 21, 2013; Accepted: November 18, 2013

Proofs received from author(s): February 5, 2014 